\title{
Basal topographic controls on the stability of the West Antarctic ice sheet: lessons from Foundation Ice Stream
}

\author{
Kathleen HUYBERS, * Gerard ROE, Howard CONWAY \\ Department of Earth and Space Sciences, University of Washington, Seattle, WA, USA. \\ E-mail: huyberkm@plu.edu
}

\begin{abstract}
Using observations of basal topography, ice thickness and modern accumulation rates, we use theory and a dynamic flowline model to examine the sensitivity of Antarctica's Foundation Ice Stream to changes in sea level, accumulation and buttressing at the grounding line. Our sensitivity studies demonstrate that the steep, upward-sloping basal topography inland from the grounding line serves to stabilize retreat of the ice stream, while the upward-sloping submarine topography downstream from the grounding line creates the potential for significant advance under conditions of modest sealevel lowering and/or increased accumulation rate. Extrapolating from Foundation Ice Stream, many nearby Weddell Sea sector ice streams are in a similar configuration, suggesting that the historical and projected responses of this sector's ice streams may contrast with those in the Amundsen or Ross Sea sectors. This work reaffirms that the greatest concerns for rapid West Antarctic Ice Sheet (WAIS) retreat are locations of reverse slopes, muted basal topography and limited lateral support.
\end{abstract}

KEYWORDS: Antarctic glaciology, glacier fluctuations, ice and climate, ice streams

\section{INTRODUCTION}

The total potential global sea-level contribution from the West Antarctic Ice Sheet (WAIS) is $\sim 4.3 \mathrm{~m}$ (Fretwell and others, 2013), and recent work suggests that Antarctica could contribute $0.15-0.62 \mathrm{~m}$ of sea-level rise in the next century (Solomon and others, 2007; Pfeffer and others, 2008; Joughin and others, 2010, 2014; Gladstone and others, 2012; Mouginot and others, 2014). However, projections of the stability of the WAIS are hampered by the complexity of ice/ocean dynamics and uncertainty in the current and projected environmental changes (Joughin and Alley, 2011; Nowicki and others, 2013). Here, we combine recent observations of ice thickness, basal topography and surface velocity (Rignot and others, 2008, 2011; Fretwell and others, 2013) with advances in theoretical understanding of ice-sheet-shelf/ocean interactions (Schoof, 2007; Gagliardini and others, 2010; Drouet and others, 2012) to gain perspective on the stability of the WAIS, using a numerical study of a shelf-terminating ice stream. The results are qualitatively extrapolated to determine implications for other WAIS ice streams.

In steady state, the flux of ice from the margins of an ice sheet is balanced by the accumulation rate integrated over the upstream catchment area. In reality, because an ice sheet is never truly in steady state, the mass balance is controlled mainly by changes in the activity of fast-flowing outlet glaciers and ice streams. These outlet glaciers respond to changing conditions at the grounding line, the transition between the grounded ice sheet and the floating ice shelf. The grounding line is, in turn, highly sensitive to changes in sea level and the melting/freezing of ice shelves. Because the ice shelves are confined by an embayment and may have some contact with the bed, they exert longitudinal compressive forces on the grounded ice that are greater than those expected from free-floating ice

* Present address: Department of Geosciences, Pacific Lutheran University, Tacoma, WA, USA. tongues. This additional compression, or buttressing, modifies the shape and flow of the upstream grounded ice (Alley and Whillans, 1991; Payne and others, 2004; Joughin and others, 2010; Pritchard and others, 2012; Shepherd and others, 2012).

Recent studies of the Thwaites and Pine Island glaciers in the Amundsen Sea sector indicate that present-day grounding line retreat is driven by ice-shelf melt and the associated decrease in buttressing (Joughin and others, 2014; Rignot and others, 2014). In contrast, our research focuses on an ice stream with a very different basal topography and shelf buttressing, Foundation Ice Stream (FIS) in the Weddell Sea sector. We use a numerical model to test the sensitivity of the FIS's grounding line to changes in sea level, accumulation and shelf buttressing, then extrapolate these findings to make a qualitative evaluation of ice streams in other sectors of the WAIS.

\section{MODEL}

Schoof (2007) provided an elegant theory for calculating the flux of ice across grounding lines. With several simplifying assumptions, the flux per unit width across a grounding line, $q\left(x_{\mathrm{g}}\right)$, can be approximated by:

$$
\begin{aligned}
q\left(x_{\mathrm{g}}\right)= & {\left[\frac{\bar{A}\left(\rho_{\mathrm{i}} g\right)^{n+1}\left(1-\left(\rho_{\mathrm{i}} / \rho_{\mathrm{w}}\right)\right)^{n}}{4^{n} C}\right]^{1 /(m+1)} } \\
& \theta^{n /(m+1)} H_{\mathrm{g}}^{(m+n+3) /(m+1)}
\end{aligned}
$$

where $x$ is the distance along a flowline, $\rho_{\mathrm{i}, \mathrm{w}}$ are the densities of ice and sea water, respectively, $g$ is the acceleration due to gravity, $\bar{A}$ is the depth-averaged temperature-dependent rheological parameter in Glen's flow law and $n$ is the corresponding exponent on the shear stress. $C$ and $m$ are parameters used to relate the basal shear stress and sliding speed: $\tau_{\mathrm{b}}=C\left|u_{\mathrm{b}}\right|^{m-1} u_{\mathrm{b}}$, a formulation frequently used in 
ice-stream studies (Pattyn and others, 2012). $H_{\mathrm{g}}$ is the ice thickness at the grounding line. Equation (1) implicitly includes the effect of an ice shelf, requiring both force- and mass-balance across the interface. The $\theta$ parameterizes the effects of ice-shelf buttressing on the longitudinal stress gradients, and varies between 0 (fully buttressed) and 1 (no buttressing). In reality, changes in buttressing depend on the evolution of the geometry of the surrounding ice shelf. While a single parameter, $\theta$, cannot capture the complexities of the dynamic stresses that the shelf imposes on the grounded ice stream, it provides a simple way to describe the back stress from buttressing and the resultant modification of the flux of ice across the grounding line.

Model parameters representing ice flow and sliding are not well constrained, but values of $n=3$, and $\bar{A}=$ $10^{-25} \mathrm{~s}^{-1} \mathrm{~Pa}^{-3}$ (appropriate for depth-averaged temperatures of $-20^{\circ} \mathrm{C}$ ) are reasonable for ice streams (Cuffey and Paterson, 2010). Reported values for $C$ vary by more than an order of magnitude, ranging from $\sim 6 \times 10^{5} \mathrm{~Pa} \mathrm{~s}^{1 / 3} \mathrm{~m}^{-1 / 3}$ for the fast-flowing Siple Coast Ice Streams to $10^{7} \mathrm{~Pa} \mathrm{~s}^{1 / 3}$ $\mathrm{m}^{-1 / 3}$ for basally resisted ice streams (Cuffey and Paterson, 2010). Values for the sliding parameter, $m$, range from $1 / 3$ for ice that is resisted laterally, to 4 for basally resisted ice. For this range of $m$, the exponent on $H_{\mathrm{g}}$ varies from 2 to 4.75. Thus, in terms of fractional changes, $q\left(x_{g}\right)$ is much more sensitive to $H_{\mathrm{g}}$ than to either buttressing $(\theta$, exponent of $0.6-2.25$ ) or flow and sliding parameters ( $A$ and $C$, exponent of 0.2-0.75).

For simplicity, hereafter we adopt a value of $m=1 / 3$ for the entire model domain; higher values of $m$ increase the importance of $H_{\mathrm{g}}$ relative to other variables, making 1/3 a conservative choice for sensitivity tests. Equation (1) has been used for several modeling experiments (Pollard and DeConto, 2009; Docquier and others, 2011), and is broadly supported by comparisons with numerical models with idealized geometries (Pattyn and others, 2012). The power law dependence on $H_{\mathrm{g}}$ in Eqn (1) also has a similar exponent to earlier theoretical work (Lingle, 1984).

Assuming hydrostatic equilibrium at the grounding line, the dominant term $H_{\mathrm{g}}$ is:

$$
H_{\mathrm{g}}=-z_{\mathrm{b}} \frac{\rho_{\mathrm{w}}}{\rho_{\mathrm{i}}},
$$

where $z_{b}$ is the bed elevation above sea level. Together, Eqns (1) and (2) suggest that $q\left(x_{\mathrm{g}}\right) \sim z_{\mathrm{b}}^{2}$ to 5 . The acute sensitivity of the flux to changes of $z_{b}$ emphasizes the importance of basal topography in the vicinity of the grounding line as a first-order control on discharge from the ice sheet. The importance of basal topography (in particular for marine ice sheets where the bed deepens inland) has been widely recognized (Weertman, 1974; Lingle, 1984; Schoof, 2007; Cofaigh and others, 2008; Pollard and DeConto, 2009; Joughin and others, 2014).

We first investigate the sensitivity of the grounding line of FIS in the Weddell Sea sector to changes in accumulation rate, sea level and buttressing at the grounding line, then discuss the implications for other outlet glaciers and ice streams. The grounding line is the location where the ice flux equals $q\left(x_{\mathrm{g}}\right)$ in Eqn (1). The ice flux is the upstream integral of the present-day accumulation, here obtained from a regional climate model (Le Brocq and others, 2010). We calculate the ice-stream profile upstream of the grounding line using a dynamic 1.5-D flowband model (Eqn (A1) in
Appendix). The grounding-line position, our main focus here, does not depend on the details of the upstream ice flow model, only on Eqn (1) and the specified accumulation. Our sensitivity experiments show that the grounding-line physics exert strong control on the advance and retreat of the ice stream.

The upper catchment of FIS is located in East Antarctica, but the ice stream flows through West Antarctica and discharges into the Filchner-Ronne Ice Shelf (Fig. 1). Like many of the ice streams in the Weddell Sea sector, the grounding line of the FIS lies in a deep (up to $1900 \mathrm{~m}$ below sea level) trench, which extends around the embayment and shoals gently out to the edge of the continental shelf (Ross and others, 2012; Fretwell and others, 2013). Basal relief just inland of the FIS grounding line rises 1400 m over $150 \mathrm{~km}$ (Fig. 2). Values for the sliding law $C(8.0 \times$ $\left.10^{6} \mathrm{~Pa} \mathrm{~s}^{1 / 3} \mathrm{~m}^{-(1 / 3)}\right)$ and $\theta=0.2$ were chosen to match the modern surface elevation profile and grounding-line position, respectively. Tuning $\theta$ and $C$ in this way assumes that the ice stream is now in equilibrium, which is consistent with recent results from cosmogenic exposure-age dating that indicate the ice stream has not thinned significantly

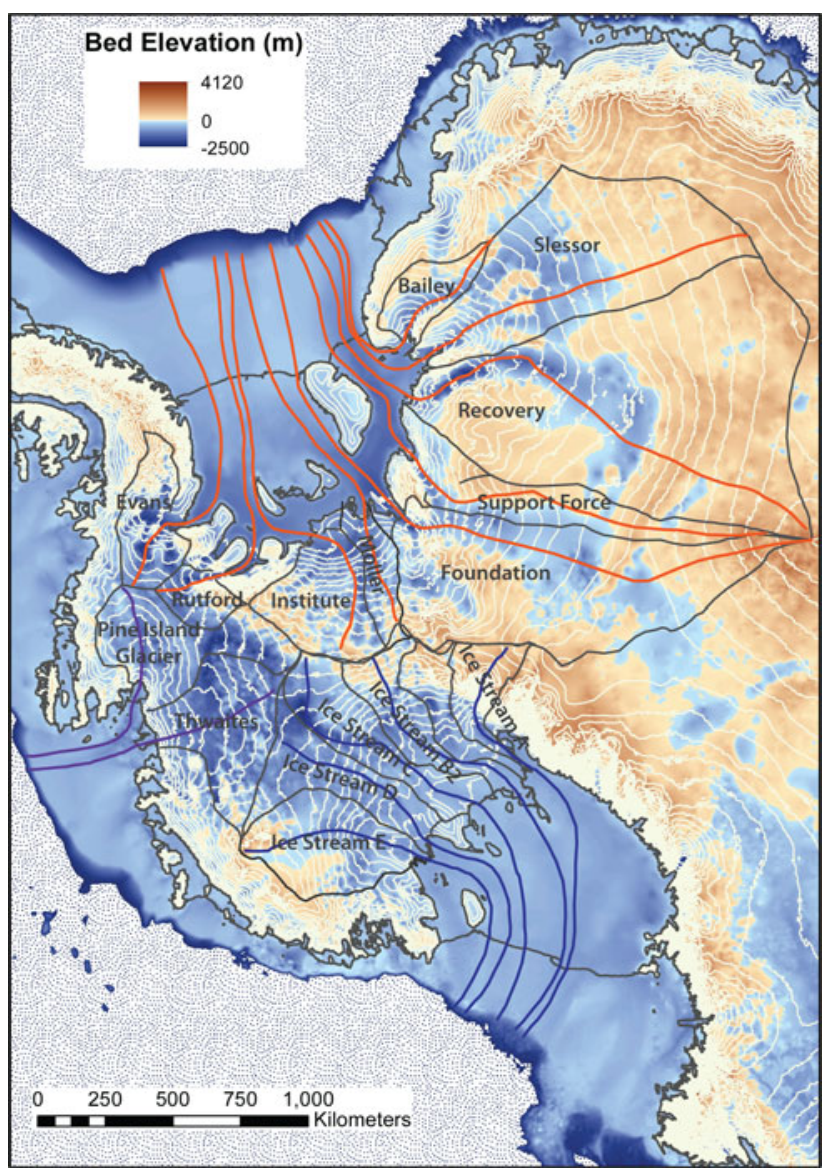

Fig. 1. Major West Antarctic ice-stream catchment areas, outlined in black (data from personal communication from I. Joughin). A characteristic flowline for each catchment area (from Byrd Polar Research Center, 1997) is overlain on Antarctica's bed elevation (Fretwell and others, 2013). Red flowlines drain to the Weddell Sea, purple to the Amundsen Sea and blue to the Ross Sea. The flowline routing beyond the present-day ice-shelf extent is drawn as a continuation of the flowline. Brown colors indicate elevations above the present-day sea level, and blue colors indicate elevations below sea level. Transition from solid to pixelated area marks the edge of the continental shelf. 


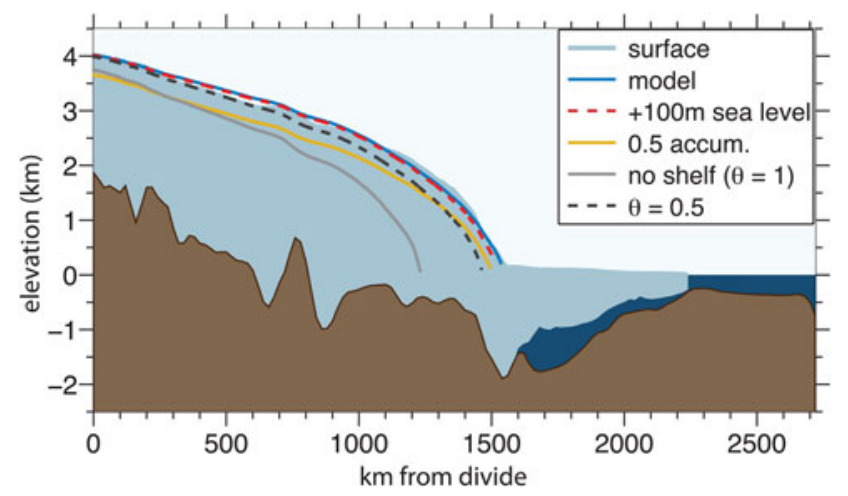

Fig. 2. FIS profile and model results. The FIS flowline from Figure 1 is interpolated onto BEDMAP2 surface elevation, bed elevation and thickness data (Fretwell and others, 2013), with the profile shown in solid colors. The bed topography has been smoothed for visual clarity, but was kept at a $1 \mathrm{~km}$ grid spacing for the model runs. The blue curve shows the initial steady-state model profile $(C=$ $8 \times 10^{6} \mathrm{~Pa} \mathrm{~s}^{1 / 3} \mathrm{~m}^{-1 / 3}, \theta=0.2$ ). The other curves show new steadystate profiles, under different environmental constraints: for sealevel rise of $100 \mathrm{~m}$ (red dashed curve); half of the present-day accumulation (yellow curve); no ice-shelf buttressing $(\theta=1)$ (solid gray curve); and partial buttressing $(\theta=0.5)$ (dashed black curve).

over the past $4000 \mathrm{ka}$ (Balco and others, 2016). Model velocities vary from 0 near the divide to more than $500 \mathrm{~m} \mathrm{a}^{-1}$ near the grounding line (consistent with observations, Rignot and others (2011)), where the assumption of pluglike sliding, rather than internal shearing deformation, accounts for more than $80 \%$ of the ice flux. Figure 2 shows that the mismatch between the modeled and observed present-day profile and the grounding-line position is small; any differences are likely due to spatial variations in bed conditions and ice flow parameters, or the three-dimensional effects that are unaccounted for in our model.

\section{RESULTS: FIS}

In all experiments, $\bar{A}, C$ and $m$ are kept constant. Results are for steady-state conditions; we do not show transient states, though internal variability and hysteresis may explain some ice stream behavior (Robel and others, 2013). Elevations throughout the text are referenced to the modern sea level. We do not correct for isostatic response or local gravitational effects (Gomez and others, 2010), both of which would tend to reduce grounding-line changes (and so our estimates are thus upper bounds in this regard), but neither would change the relative importance of different climatic factors.

We caution that the calculations are not intended as projections or recreations of historical grounding-line positions and upstream ice profiles; parametrizations of deformation and sliding are uncertain and full thermomechanical details are not included. Rather, our results are a quantitative demonstration of the physical principles embodied in Eqns (1), (2), (A1) and (A2).

First, we consider forcings that would cause the grounding line of the FIS to retreat. An unrealistically large sea-level increase of $100 \mathrm{~m}$ requires grounding-line retreat of only 5 $\mathrm{km}$ to restore balance (Fig. 2, dashed red line). The steep basal topography inland of the grounding line can accommodate this change over relatively short horizontal scales, and is accompanied by very little change in ice thickness.
Halving the upstream accumulation rate is balanced by a grounding-line retreat of only $\sim 18 \mathrm{~km}$ (Fig. 2, yellow line). In contrast to sea-level rise, the reduced accumulation causes interior thinning that averages $180 \mathrm{~m}$ over the domain of the grounded ice.

Complete removal of buttressing (setting $\theta=1$ in Eqn (1)) causes the largest change. The grounding line retreats $\sim 300$ $\mathrm{km}$ before re-stabilizing near the edge of the trench, and the interior thins, reducing the volume of ice by $28 \%$ (Fig. 2, dark gray line). Smaller changes in buttressing have less effect setting $\theta=0.5$ causes the grounding line to retreat by only $75 \mathrm{~km}$, with an ice-volume loss of $\sim 5 \%$ (Fig. 2, dashed black line).

We now turn to the factors that might cause an advance of FIS. Because the FIS's grounding line presently lies in the deepest part of its domain, an increase in the flux cannot be accommodated by an advance in the grounding line due to the shallowing topography (Eqn (1)). Lowering the sea level by only $23 \mathrm{~m}$ (well above the Last Glacial Maximum (LGM) sea level) or increasing the accumulation uniformly by $6 \%$ results in a grounding line advance to the edge of the continental shelf. Although model uncertainties are high, this highlights how complex grounding-line dynamics might produce counter-intuitive consequences to environmental change. They serve as a quantitative demonstration of the physical principle embodied in Eqn (1): that a large forcing is necessary to induce retreat from the trench in which the present-day grounding line resides, but a relatively small forcing is sufficient to advance the grounding line on a long, reverse-slope bed.

The location of the FIS grounding line is key to its current stability with respect to retreat. Because the upstream gradient of the bed is so steep, relatively small changes in the grounding-line position can accommodate large changes in ice flux. While the modern FIS geometry suggests it is stable to retreat, we note that the long reverse-slope seaward of the present-day grounding line cannot sustain a stable grounding-line position, implying that the FIS is relatively unstable to advances, and that during glacial periods the grounding line could readily push well beyond its present location, advancing to the edge of the continental shelf. This theoretical argument for a significant advancement during the last glacial period is corroborated by marine-geological evidence (Hillenbrand and others, 2012), and other modeling efforts (Stolldorf and others, 2012; Whitehouse and others, 2012) and by glacial geological data from the Williams Hills $50 \mathrm{~km}$ upstream from the grounding line that show the ice stream there was 500 $\mathrm{m}$ thicker during the LGM (Balco and others, 2016). However, our model cannot establish for how long such an advance would be stable; for instance, the added ice volume would further depress the bed, raising relative sea level higher and mitigating runaway advance. Moreover, the redistribution of ice shelves would impact buttressing, an effect that is also omitted here.

\section{APPLICATION TO OTHER ICE STREAMS AND SECTORS}

The analyses from the previous section underscore the predominant importance of basal topography for grounding-line sensitivity, and motivate exploring the potential implications for the sensitivity of other ice streams. It should be emphasized that such an evaluation is only a qualitative interpretation. 
FIS's position in a deep trench is characteristic of several other outlets. Many of the other ice streams that flow into the Ronne-Filchner Ice Shelf are also grounded within the deep asymmetrical trench that rings the Weddell Sea embayment. Support-Force, Recovery, Rutford, and Evans Ice Streams all have beds that rise steeply inland immediately behind the present-day position of the grounding line (Figs $1,3 \mathrm{~b}, \mathrm{c}, \mathrm{h}, \mathrm{i})$, implying that they are also stable to plausible future sea-level rise or decreases in shelf buttressing. Moreover, with the exception of Recovery Ice Stream, the bed generally shoals toward the continental shelf, indicating the potential for expansion of the ice sheet when sea level lowered during glacial periods. The grounding lines of Slessor, Bailey, Möller and Institute Ice Streams (Figs 1, 3d, $\mathrm{e}, \mathrm{f}, \mathrm{g}$ ) lie just beyond the deep trench. For these ice streams, a relatively small external forcing may cause an initial grounding retreat on the order of $\sim 100 \mathrm{~km}$, but stability would be re-acquired in the deep trenches. Note that Slessor Ice Stream is currently grounded on a reverse slope; this potentially unstable position implies a more complex role for buttressing than is represented by Eqn (1). One possibility is lateral communication of buttressing between adjacent ice streams through thickness changes on lightly grounded ice plains, as inferred by Hulbe and Fahnestock (2007).

In contrast, the variations in basal topography beneath the ice streams in the Ross Sea sector are small (Figs 1, 3j-n). Over regional scales (a few hundred kilometers), the ice streams are grounded on gentle reverse slopes that extend in both directions from the current grounding line. The large-scale basal topography suggests that both advances and retreats would be determined by the complex interplay of basal topography, external forcing factors and influence from adjacent ice streams, mediated by ice-shelf buttressing and competition for upstream catchment area. Further, thermomechanical feedbacks that control basal sliding of the Ross Ice Streams (Raymond, 1996) may lead to stagnation and reactivation of flow over century scales (Hulbe and Fahnestock, 2007; Robel and others, 2013) and even switches of flow direction (Conway and others, 2002), adding complexity to projections of future behaviors. In addition, small-scale sea mounts and lateral buttressing from interstream ridges along the Siple Coast influence grounding-line advance and retreat (Gagliardini and others, 2010; Drouet and others, 2012).

The Amundsen Sea sector is currently well out of balance $\left(-64 \mathrm{Gt} \mathrm{a}^{-1}\right.$, Rignot and others (2008)). Further, the current grounding lines of Thwaites and Pine Island Glaciers are positioned at the edge of an overdeepening that extends below sea level more than $400 \mathrm{~km}$ inland (Figs 1, 3o, p). If the current rates of melting and disintegration of surrounding ice shelves continues (Pritchard and others, 2012), the glaciers could retreat more than $300 \mathrm{~km}$ inland, perhaps temporarily held up at numerous small bedrock bumps.

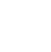

(a)

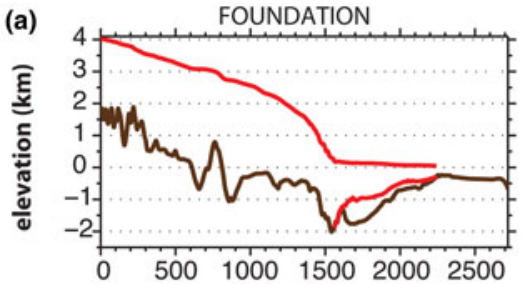

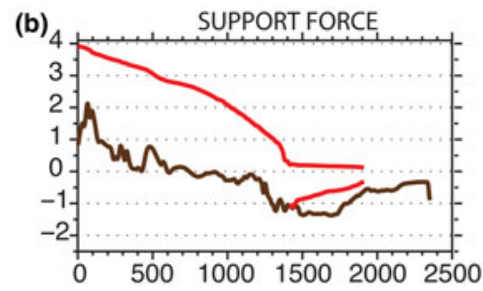

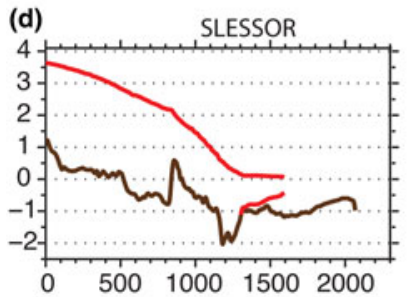

(c)

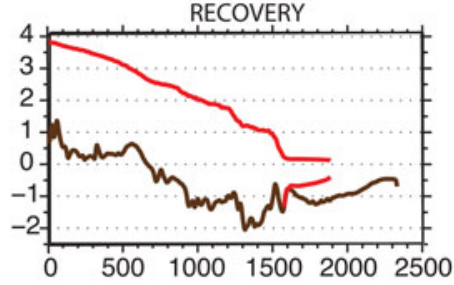

(g)

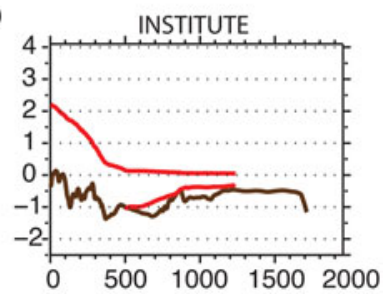

(k)

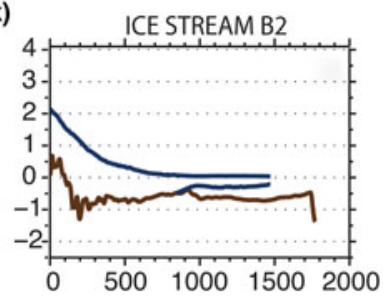

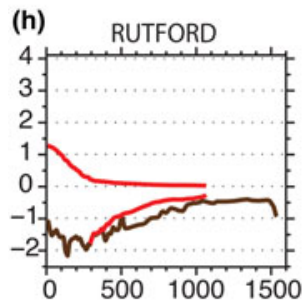

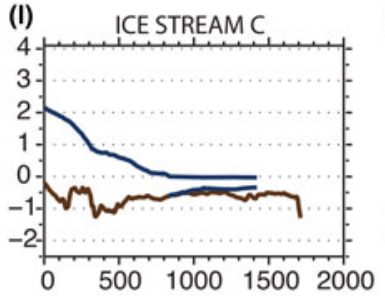

(i)

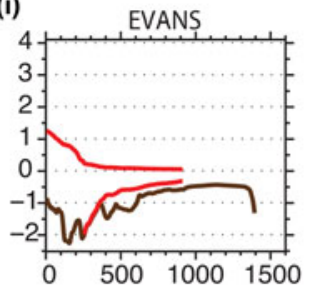

(m) ICE STREAM D

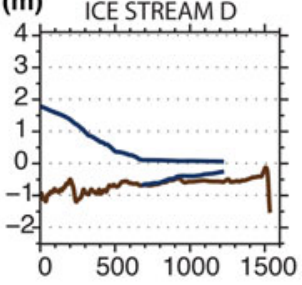

(e) BAILEY (f)

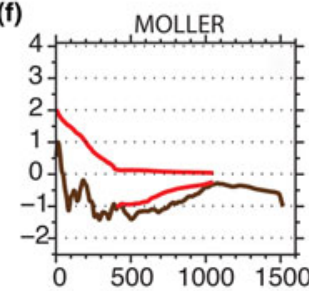

(j)

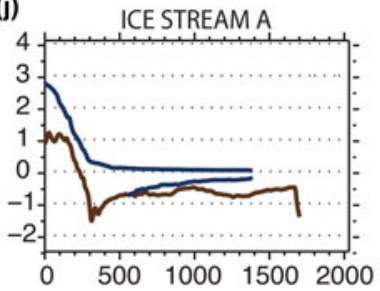

$0 \quad 500 \quad 1000 \quad 15002000$

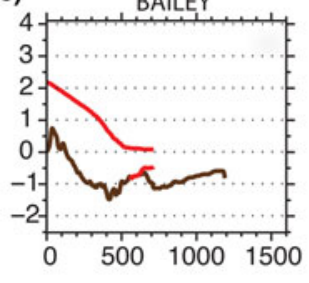




\section{CONCLUSIONS}

Quantitative projections of the future of the WAIS and a detailed understanding of past changes are hampered by uncertainties relating to the complex interactions in the ice, ocean and atmospheric dynamics in the region. Key factors are ice-sliding rheology, buttressing and isostatic response. It is yet to be established whether such projections and reconstructions are a tractable goal. While accurate predictions may remain elusive, the robust physical constraints embodied in Eqn (1), together with new bedrock data, can provide insight into relative stability of the ice streams in the Weddell, Amundsen and Ross Sea sectors of Antarctica to the same environmental forcing.

The focus in this study has been the acute functional sensitivity of the grounding-line flux to basal topography $\left(q\left(x_{\mathrm{g}}\right) \sim z_{\mathrm{b}}^{2}\right.$ to 5$)$. This implies that ice streams like FIS that are grounded in bathymetric trenches may be quite stable to retreat, but relatively unstable to advance. It also implies that even small topographic ridges can locally anchor grounding lines, even if the larger scale topography is a reverse slope (Schoof, 2007). Our evaluation reaffirms that the greatest concerns for WAIS retreat are locations of reverse slopes, muted basal topography and limited lateral support.

\section{SUPPLEMENTARY MATERIAL}

The supplementary material for this article can be found at https://doi.org/10.1017/aog.2017.9.

\section{ACKNOWLEDGEMENTS}

Funding was provided by the US National Science Foundation (ANT-083783, ANT-0838784, and ANT0838256). We thank Greg Balco, Claire Todd, Seth Campbell and Ed Waddington for thoughtful discussions and insights. We also thank Raytheon Polar Services, Ken Borek Air, UNAVCO and the New York Air National Guard, for logistical support in Antarctica.

\section{REFERENCES}

Alley RB and Whillans IR (1991) Changes in the West Antarctic Ice Sheet. Science, 254(5034), 959-963

Balco G and 7 others (2016) Cosmogenic-nuclide exposure ages from the Pensacola Mountains adjacent to the Foundation Ice Stream, Antarctica. Am. J. Sci., 316, 542-577

Byrd Polar Research Center (1997) RADARSAT-1 Antarctic Mapping Project Data. http://research.bpcrc.osu.edu/rsl/radarsat/data/

Cofaigh CÓ, Dowdeswell JA, Evans J and Larter RD (2008) Geological constraints on Antarctic palaeo-ice-stream retreat. Earth Surf. Process. Landf., 33(4), 513-525

Conway H and 5 others (2002) Switch of flow direction in an Antarctic ice stream. Nature 419(6906), 465-467

Cuffey KM and Paterson WSB (2010) The Physics of Glaciers. Elsevier Science

Docquier D, Perichon L and Pattyn F (2011) Representing grounding line dynamics in numerical ice sheet models: recent advances and outlook. Surv. Geophys., 32(4-5), 417-435

Drouet A and 6 others (2012) Grounding line transient response in marine ice sheet models. Cryosphere Discuss., 6, 3903-3935

Fretwell P and 59 others. (2013) Bedmap2: improved ice bed, surface and thickness datasets for Antarctica. Cryosphere, 7(1)

Gagliardini O, Durand G, Zwinger T, Hindmarsh R and Le Meur E (2010) Coupling of ice-shelf melting and buttressing is a key process in ice-sheets dynamics. Geophys. Res. Lett., 37(14)
Gladstone RM and 9 others (2012) Calibrated prediction of Pine Island Glacier retreat during the 21 st and 22nd centuries with a coupled flowline model. Earth Planet. Sci. Lett., 333, 191-199

Gomez N, Mitrovica JX, Huybers P and Clark PU (2010) Sea level as a stabilizing factor for marine-ice-sheet grounding lines. Nat. Geosci., 3(12), 850-853

Hillenbrand C-D, Melles M, Kuhn G and Larter RD (2012) Marine geological constraints for the grounding-line position of the Antarctic Ice Sheet on the southern Weddell Sea shelf at the Last Glacial Maximum. Quat. Sci. Rev., 32, 25-47

Hulbe C and Fahnestock M (2007) Century-scale discharge stagnation and reactivation of the Ross ice streams, West Antarctica. J. Geophys. Res.: Earth Surf. (2003-2012), 112(F3)

Joughin I and Alley RB (2011) Stability of the West Antarctic ice sheet in a warming world. Nat. Geosci., 4(8), 506-513

Joughin I and Bamber JL (2005) Thickening of the ice stream catchments feeding the Filchner-Ronne Ice Shelf, Antarctica. Geophys. Res. Lett., 32(17)

Joughin I, Smith BE and Holland DM (2010) Sensitivity of 21st century sea level to ocean-induced thinning of Pine Island Glacier, Antarctica. Geophys. Res. Lett., 37(20)

Joughin I, Smith BE and Medley B (2014) Marine ice sheet collapse potentially under way for the Thwaites Glacierbasin, West Antarctica. Science, 344(6185), 735-738 (doi: 10.1126/ science.1249055)

Le Brocq AM, Payne AJ and Vieli A (2010) An improved Antarctic dataset for high resolution numerical ice sheet models (ALBMAP v1). Earth Syst. Sci. Data Discus., 3(1), 195-230

Lingle CS (1984) A numerical model of interactions between a polar ice stream and the ocean: application to ice stream E, West Antarctica. J. Geophys. Res.: Oceans (1978-2012), 89(C3), 3523-3549

Mouginot J, Rignot E and Scheuchl B (2014) Sustained increase in ice discharge from the Amundsen Sea Embayment, West Antarctica, from 1973 to 2013. Geophys. Res. Lett., 41(5), 1576-1584

Nowicki S and 9 others. (2013) Insights into spatial sensitivities of ice mass response to environmental change from the SeaRISE ice sheet modeling project II: Greenland. J. Geophys. Res.: Earth Surf., 118(2), 1025-1044

Oerlemans J (2001) Glaciers and climate change. CRC Press

Pattyn F and 9 others. (2012) Results of the marine ice sheet model intercomparison project, MISMIP. Cryosphere Discus., 6(1), 267-308

Payne AJ, Vieli A, Shepherd AP, Wingham DJ and Rignot E (2004) Recent dramatic thinning of largest West Antarctic ice stream triggered by oceans. Geophys. Res. Lett., 31(23)

Pfeffer WT, Harper J and O'Neel S (2008) Kinematic constraints on glacier contributions to 21 st-century sea-level rise. Science, $\mathbf{3 2 1}$ (5894), 1340-1343

Pollard D and DeConto RM (2009) Modelling West Antarctic ice sheet growth and collapse through the past five million years. Nature, 458(7236), 329-332

Pritchard $\mathrm{H}$ and 5 others (2012) Antarctic ice-sheet loss driven by basal melting of ice shelves. Nature, 484(7395), 502-505

Raymond C (1996) Shear margins in glaciers and ice sheets. J. Glaciol., 42(140), 90-102

Rignot E and 6 others (2008) Recent Antarctic ice mass loss from radar interferometry and regional climate modelling. Nat. Geosci., 1(2), 106-110

Rignot E, Mouginot J and Scheuchl B (2011) Ice flow of the Antarctic ice sheet. Science, 333(6048), 1427-1430

Rignot E, Mouginot J, Morlighem M, Seroussi H and Scheuchl B (2014) Widespread, rapid grounding line retreat of Pine Island, Thwaites, Smith, and Kohler glaciers, West Antarctica, from 1992 to 2011. Geophys. Res. Lett., 41(10), 3502-3509

Robel AA, DeGiuli E, Schoof C and Tziperman E (2013) Dynamics of ice stream temporal variability: modes, scales, and hysteresis. J. Geophys. Res.: Earth Surf., 118(2), 925-936

Ross $\mathrm{N}$ and 9 others (2012) Steep reverse bed slope at the grounding line of the Weddell Sea sector in West Antarctica. Nat. Geosci., $\mathbf{5}$ (6), 393-396 
Schoof C (2007) Ice sheet grounding line dynamics: steady states, stability, and hysteresis. J. Geophys. Res.: Earth Surf. (2003-2012), 112(F3) Shepherd A and 9 others. (2012) A reconciled estimate of ice-sheet mass balance. Science, 338(6111), 1183-1189

Solomon S, I. P. on Climate Change, and I. P. on Climate Change and Working Group I. (2007) Climate change 2007 - the physical science basis: working group I contribution to the fourth assessment report of the IPCC. Assessment Report (Intergovernmental Panel on Climate Change): Working Group, Cambridge University Press, Cambridge, United Kingdom and New York, NY, USA
Stolldorf T, Schenke H-W and Anderson JB (2012) LGM ice sheet extent in the Weddell Sea: evidence for diachronous behavior of Antarctic ice sheets. Quat. Sci. Rev., 48, 20-31

Weertman J (1974) Stability of the junction of an ice sheet and an ice shelf. J. Glaciol., 13, 3-11

Whitehouse PL, Bentley MJ and Le Brocq AM (2012) A deglacial model for Antarctica: geological constraints and glaciological modelling as a basis for a new model of Antarctic glacial isostatic adjustment. Quat. Sci. Rev., 32, 1-24 